\title{
Van-Gogh-like 2 antagonises the canonical WNT pathway and is methylated in colorectal cancers
}

\author{
G Piazzi ${ }^{1,2,3}$, M Selgrad ${ }^{1,4}$, M Garcia ${ }^{1}$, C Ceccarelli ${ }^{5}$, L Fini ${ }^{1,6}$, P Bianchi ${ }^{6}$, L Laghi $^{6}$, L D $^{\prime}$ Angelo $^{2}$,
} P Paterini ${ }^{3}$, P Malfertheiner ${ }^{4}$, P Chieco ${ }^{2}$, C R Boland ${ }^{1}$, F Bazzoli ${ }^{3}$ and L Ricciardiello*,1,2,3

${ }^{1}$ Department of Internal Medicine, Baylor Research Institute and Sammons Cancer Center, Baylor University Medical Center, 3500 Gaston Avenue, Dallas, TX 75246, USA; ${ }^{2}$ Center for Applied Biomedical Research (CRBA), S. Orsola-Malpighi Hospital, University of Bologna, Bologna, Italy; ${ }^{3}$ Department of Medical and Surgical Sciences, University of Bologna, via Massarenti 9, Bologna 40138, Italy; ${ }^{4}$ Department of Gastroenterology, Hepatology and Infectious Diseases, Otto-von-Guericke University of Magdeburg, Leipziger Street 44, Magdeburg D-39120, Germany; ${ }^{5}$ Department of Experimental, Diagnostic and Specialty Medicine, S.OrsolaMalpighi Hospital, University of Bologna, via Massarenti 9, Bologna 40138, Italy and ${ }^{6}$ Department of Gastroenterology, Humanitas Clinical and Research Center, via Manzoni 56, Milan 20089, Italy

Background: Aberrant activation of the canonical WNT signaling is a feature of colorectal cancer (CRC). Van-Gogh-like 2 (VANGL2) belongs to the non-canonical WNT pathway whose activation inhibits canonical WNT signaling. In this study, we investigated the role of VANGL2 and its epigenetic regulation in CRC.

Methods: Van-Gogh-like 2 expression and promoter methylation after 5-aza-2'-deoxycytidine (5-aza) treatment were evaluated in CRC cells. DNA samples from 418 sporadic CRCs were tested for VANGL2 promoter methylation and microsatellite instability (MSI). Proliferation, colony formation and activation of the WNT pathway were tested in cells after VANGL2 overexpression.

Results: Van-Gogh-like 2 mRNA was significantly higher in 5-aza-treated RKO, LOVO and SW48, whereas no differences were found in SW480. Van-Gogh-like 2 was fully methylated in RKO, SW48, HCT116, DLD1 and Caco2; partially methylated in LOVO, LS174T and SW837; and unmethylated in SW480, SW620 and HT29. Higher expression of VANGL2 mRNA was found in the unmethylated cell lines. In CRC specimens (8.93\% MSI), methylated VANGL2 was associated with MSI, higher grade, proximal colon location and BRAF mutation. Van-Gogh-like 2 overexpression in SW480 significantly decreased proliferation, colony formation and $\beta$-catenin levels.

Conclusion: Van-Gogh-like 2 is frequently methylated in MSI-CRCs with BRAF mutation and may act as a tumour suppressor gene, counteracting WNT/ $\beta$-catenin signaling.

Epigenetic silencing of tumour suppressor genes (TSGs) by promoter methylation represents a key mechanism for their inactivation during tumorigenesis (Baylin and Ohm, 2006). Aberrant widespread promoter hypermethylation of TSG is typical of colorectal cancers (CRCs) displaying the CpG Island Methylator Phenotype or CIMP (Toyota et al, 1999), whereas somatic biallelic hypermethylation of the hMLH1 promoter is associated with the microsatellite instability (MSI) phenotype in sporadic CRCs (Kane et al, 1997). Microsatellite instability results from inactivation of the DNA mismatch repair system and is observed in approximately $15 \%$ of CRCs (12\% sporadic and 3\% associated with Lynch syndrome), whereas the remaining $85 \%$ of CRCs are microsatellite stable (MSS) and often display chromosomal instability (CIN; Grady and Carethers, 2008; Boland and Goel, 2010; Pino and Chung, 2010). Microsatellite unstable tumours typically arise in the proximal colon, display mucinous histology, as well as lymphocytic

*Correspondence: Dr L Ricciardiello; E-mail: luigi.ricciardiello@unibo.it

Received 22 January 2013; revised 10 March 2013; accepted 11 March 2013; published online 11 April 2013

(c) 2013 Cancer Research UK. All rights reserved 0007-0920/13 
infiltration, are clinically favourable compared with MSS tumours but respond poorly to 5-fluorouracil-based chemotherapy (Sinicrope and Sargent, 2012). Sporadic MSI tumours associated with CIMP are tightly associated with mutation in BRAF gene (V600E; Weisenberger et al, 2006). Although the importance of methylation in defining different CRC subtypes is now unfolding, the specific methylation events that contribute to these subtypes are still unclear.

The WNT signaling pathway in vertebrates is divided into the canonical and non-canonical (Veeman et al, 2003; Logan and Nusse, 2004). Activation of the canonical WNT/ $\beta$-catenin signaling leads to tumorigenesis in many cancers, including CRC (Reya and Clevers, 2005). An important function of the $\beta$-cateninindependent or non-canonical WNT signaling is the regulation of planar cell polarity (PCP; Barrow, 2006). The PCP pathway is important for directing polarisation of cells orthogonal to the axis of apical-basal polarity within the plane of an epithelium. VanGogh-like 2 (VANGL2) is a member of the non-canonical WNT/ PCP signaling pathway, originally identified in Drosophila melanogaster, which is critical for establishment of the PCP of cells within epithelial sheets (Taylor et al, 1998; Wolff and Rubin, 1998). Van-Gogh-like 2 encodes a predicted four-pass transmembrane scaffolding protein with a PDZ domain-binding motif at the carboxy-terminus involved in protein-protein interactions (Torban et al, 2004; Iliescu et al, 2011). Van-Gogh-like 2 has been reported to interact with Rac1 (a small Rho-like GTPase) to regulate adherens junctions during PCP signaling in vertebrates (Lindqvist et al, 2010). Moreover, VANGL2 has been found to interact with Rack1 (receptor for activated C kinase 1) and this interaction is required for VANGL2 membrane localisation and PCP signaling (Li et al, 2011). Recently, VANGL2 has been demonstrated to form with Ror2 (receptor tyrosine kinase-like orphan receptor 2), a WNT-5a-induced receptor complex essential to establish PCP. In humans and mice (Lp/Lp homozigotes), VANGL2 mutations lead to miscarried fetuses with neural tube defects (Kibar et al, 2001; Lei et al, 2010; Kibar et al, 2011). In addition, VANGL2 has been also shown to regulate collective migration and invasion of human fibrosarcoma cells regulating matrix metalloproteinase 14 (MMP14) membrane trafficking (Cantrell and Jessen, 2010; Williams et al, 2012). A possible role of VANGL2 in CRC has not been investigated yet.

In an attempt to shed more light on epigenetically silenced genes in CRC, we identified VANGL2 during a cRNA microarray screening of a panel of CRC cell lines treated with the demethylating agent 5-aza. First, we analysed VANGL2 promoter methylation and expression in CRC cell lines. Then, we investigated the promoter methylation status of this gene in 418 sporadic CRC cases examining associations with clinico-pathological characteristics. We found that VANGL2 promoter methylation is associated with MSI subtype and BRAF mutation. As promoter methylation in non-canonical ligands and receptors has been associated with MSI in CRC patients (Rawson et al, 2011) and $\mathrm{WNT} / \beta$-catenin activation in CRC cell lines (Ying et al, 2008; Lara et al, 2010), we hypothesised that loss of VANGL2 by aberrant promoter hypermethylation in MSI CRCs could have a protumorigenic role in $\mathrm{CRC}$ via $\mathrm{WNT} / \beta$-catenin activation. Here we report that ectopic expression of VANGL2 can suppress cell growth and clonogenicity by $\mathrm{WNT} / \beta$-catenin suppression, suggesting that VANGL2 could be a TSG in CRC.

\section{MATERIALS AND METHODS}

Cell lines and treatments. Colorectal cancer cell lines RKO, SW480, SW48, HCT116, LOVO, DLD1, LS174T, SW620, Caco2, HT29 and SW837 were obtained from ATCC (Manassas, VA,
USA). In our laboratory, all cells are tested and authenticated every 6 months using known genetic and epigenetic markers. Cells were cultured in IMDM or Leibovitz medium (the latter only for SW620) supplemented with $10 \%$ fetal bovine serum, $100 \mathrm{U} \mathrm{ml}^{-1}$ penicillin, $100 \mu \mathrm{g} \mathrm{ml}^{-1}$ streptomycin and $2 \mathrm{mM}$ glutamine (Invitrogen, Carlsbad, CA, USA). Cells were maintained at $37^{\circ} \mathrm{C}$ in a $5 \% \mathrm{CO}_{2}$ incubator.

5-Aza-2'deoxycytidine (5-aza) was purchased from Sigma-Aldrich (St Louis, MO, USA) and the treatment was performed on RKO, SW480, SW48, HCT116, LOVO cell lines at $1-5 \mu \mathrm{M}$ for $96 \mathrm{~h}$.

The full VANGL2-coding sequence was cloned into the pCMVTag1 expression vector (Stratagene, La Jolla, CA, USA), using SacI and KpnI restriction enzymes (NEB, Ipswich, MA, USA). Transfection of pCMV-VANGL2 was performed using Lipofectamine 2000 (Invitrogen), following the manufacturer's protocol, and after $48 \mathrm{~h}$, cells were selected using G418 at a concentration established with the killing curve $\left(1.5 \mathrm{mg} \mathrm{ml}^{-1}\right.$ for SW480 and $0.4 \mathrm{mg} \mathrm{ml}^{-1}$ for HCT116).

Bisulphite sequencing and methylation-specific PCR (MSP). The methylation status of the VANGL2 promoter in CRC cell lines and tissues was determined by bisulphite sequencing and MSP after treating $1 \mu \mathrm{g}$ of DNA with sodium bisulphite with the Epitect Bisulfite Kit (Qiagen, Valencia, CA, USA), following the manufacturer's protocol. Modified DNA was used as a template for PCR reactions. For the bisulphite sequencing, primers amplifying a sequence located in the $5^{\prime}$ UTR between -15128 and -14863 from the transcriptional start codon, containing $42 \mathrm{CpGs}$, were selected. Two microliters of PCR products were ligated into the TOPO vector (Invitrogen) and, after transformation, at least eight clones per sample were sequenced in both directions with M13 primers. Methylation-specific PCR was performed in a representative region of the $5^{\prime} \mathrm{UTR}$, spanning -15072 through -14978 from the transcriptional start codon. Primer sequences are listed in Supplementary Table 1.

RNA extraction and quantitative RT-PCR. RNA extraction from cells was performed with TRIzol (Invitrogen) and $2 \mu \mathrm{g}$ of total RNA were retrotranscribed using oligo-dT and MMLV reverse transcriptase (Invitrogen). Quantification of VANGL2 was performed by quantitative reverse transcriptase PCR (Q-RT-PCR) using Taqman Gene Expression Assay (Hs00393412_m1, Applied Biosystems, Carlsbad, CA, USA). GAPDH was used as reference gene. The relative quantification of VANGL2 gene expression was performed with the comparative CT method $\left(2^{-\Delta \Delta \mathrm{Ct}}\right)$, using the untreated cell line (CTRL) or a pool of healthy subjects as a calibrator. For 5-aza experiments, a ratio between VANGL2 mRNA expression after and before 5-aza treatment was calculated. Each evaluation was performed in triplicate.

Protein extraction and western blotting. Total protein extraction from cell lines was performed using RIPA buffer (Santa Cruz Biotechnology, Santa Cruz, CA, USA) supplemented with protease and phosphatase inhibitors (Roche, NJ, USA). Forty micrograms of proteins were separated on a $10 \%$ SDS-PAGE, transferred onto PVDF membrane (GE Healthcare, NJ, USA) and probed with the following primary antibodies: goat anti-VANGL2 at $1: 1000$ (Santa Cruz Biotechnology) and mouse anti- $\beta$-actin at $1: 1000$ (SigmaAldrich). After incubation with the specific secondary antibody, proteins were visualised using the ECL Plus Chemiluminescence system with a Storm 840 PhosphorImager (GE Healthcare). The housekeeping protein $\beta$-actin was used to normalise protein expression levels.

Luciferase activity assay. One-microgram per well of TOPflash TCF reporter plasmid (Millipore, MA, USA) was co-transfected with a thymidine kinase promoter-driven Renilla luciferase (40 ng per well) plasmid as a reference control (Promega, Madison, WI, USA). Luciferase activity was assayed $24 \mathrm{~h}$ after using the 
Dual-Luciferase Reporter Assay System (Promega), according to the manufacturer's instructions. Luciferase activity was normalised to Renilla activity. Experiments were performed in triplicate.

Immunofluorescence. Cells were seeded onto glass coverslips at $60 \%$ confluence, fixed with $2 \%$ paraformaldehyde and permeabilised with $0.2 \%$ Triton X-100. Cells were incubated with mouse anti- $\beta$-catenin antibody (Santa Cruz Biotechnology) and secondary Texas Red-conjugated anti-mouse antibody (Dako Cytomation, Glostrup, DK, USA).

Colony-forming assay. Cells were seeded at the density of 100 cells per well in six-well plates, and after 2 weeks cells were fixed with $0.5 \%$ crystal violet in paraformaldehyde. The total number of visible colonies was counted. Three independent experiments were performed in triplicate.

Clinical samples. Formalin-fixed, paraffin-embedded (FFPE) tissues from 418 sporadic CRC were obtained from the Department of Gastroenterology, Humanitas Clinical and Research Center, Rozzano (Milan, Italy; 'Milan samples') and from the Clinical Department of Radiological and Histopathological Sciences, S.Orsola-Malpighi Hospital, University of Bologna (Bologna, Italy; 'Bologna samples'). Seventeen FFPE normal colon samples were obtained from the Department of Gastroenterology, Hepatology and Infectious Diseases, Otto-von-Guericke University Magdeburg, Magdeburg, Germany. Information about grading was missing from 12 samples.

Informed written consent was obtained before procedures. Institutional Review Board approval was granted for this study.

DNA extraction and BRAF and KRAS mutational analyses. DNA extraction was done by tissue microdissection from tumour areas of FFPE tissue slides using the QIAamp DNA Mini kit according to the manufacturer's protocol (Qiagen). BRAF exon 15, which contains the V600E mutation, and KRAS codon 12/13 mutations were amplified using primers reported in Supplementary Table 1. PCR was performed for 30 cycles as follows: $95^{\circ} \mathrm{C}$ for $30 \mathrm{~s}, 57^{\circ} \mathrm{C}$ for $30 \mathrm{~s}$ and $72^{\circ} \mathrm{C}$ for $30 \mathrm{~s}$. This was followed by an extension step at $72^{\circ} \mathrm{C}$ for $10 \mathrm{~min}$. PCR products were separated on an agarose gel, purified and sequenced using a Beckman Coulter sequencer CEQ 8000 (Beckman Coulter, Milan, Italy). BRAF data were obtained from 172 samples.

Microsatellite instability testing. Microsatellite instability was assessed differently in the two sets of patients. In 'Bologna samples', MSI was tested using five mononucleotide markers (Ricciardiello et al, 2005). A high degree of MSI was defined as the presence of mutations in $\geqslant 30 \%$ of the markers; a low degree of MSI (MSI-L) was defined as at least one mutation in $<30 \%$ of the markers; MSS was defined as no mutant markers (Boland et al, 1998). For statistical purposes, MSI-L cancers were considered together with MSS. In 'Milan samples', MSI was tested using the mononucleotide markers BAT26 and BAT25 and defined by frameshifts at either one or both markers. Loss of expression of MMR proteins was confirmed in all MSI CRC by immunohistochemistry (Laghi et al, 2008). Microsatellite data were available from 392 samples.

Statistical analysis. Unpaired $t$-tests were used to evaluate the mean differences between two groups for the continuous variables. Chi-square and Fisher's exact test were applied to analyse categorical variables. Correspondence analysis, a graphic exploratory technique, was used to explore associations between different categories (Greenacre, 1984) in two- and multi-way contingency tables. Logistic regression analysis was used to analyse associations between different categories. JMP version 8.02 (Cary, NC, USA), SAS version 9.2 (Cary, NC, USA) and BMDP Statistical Software Inc. (BMDP PC-90 Statistical Software, Los Angeles, CA, USA) were used for the statistical analysis. Significance was assigned at $P<0.05$.

\section{RESULTS}

Van-Gogh-like 2 expression in CRC cell lines is regulated by promoter methylation. We identified VANGL2 gene expression using a cRNA microarray approach to find new epigenetically regulated targets in CRC cell lines with different molecular profiles (RKO and SW48, MSI-CIMP; HCT116 and LOVO, MSI-Lynch; SW480, MSS) after treatment with the demethylating agent 5-aza (Supplementary Figure 1). Q-RT-PCR was performed to confirm the cRNA microarray data (Figure 1A). We found that VANGL2 expression was higher in 5-aza-treated RKO, LOVO, SW48 $(P<0.05)$ and HCT116 (although not reaching a statistical significance in HCT116) compared with untreated cell lines. No differences were found in SW480 after treatment with 5-aza (unpaired $t$-test) (Figure 1A).
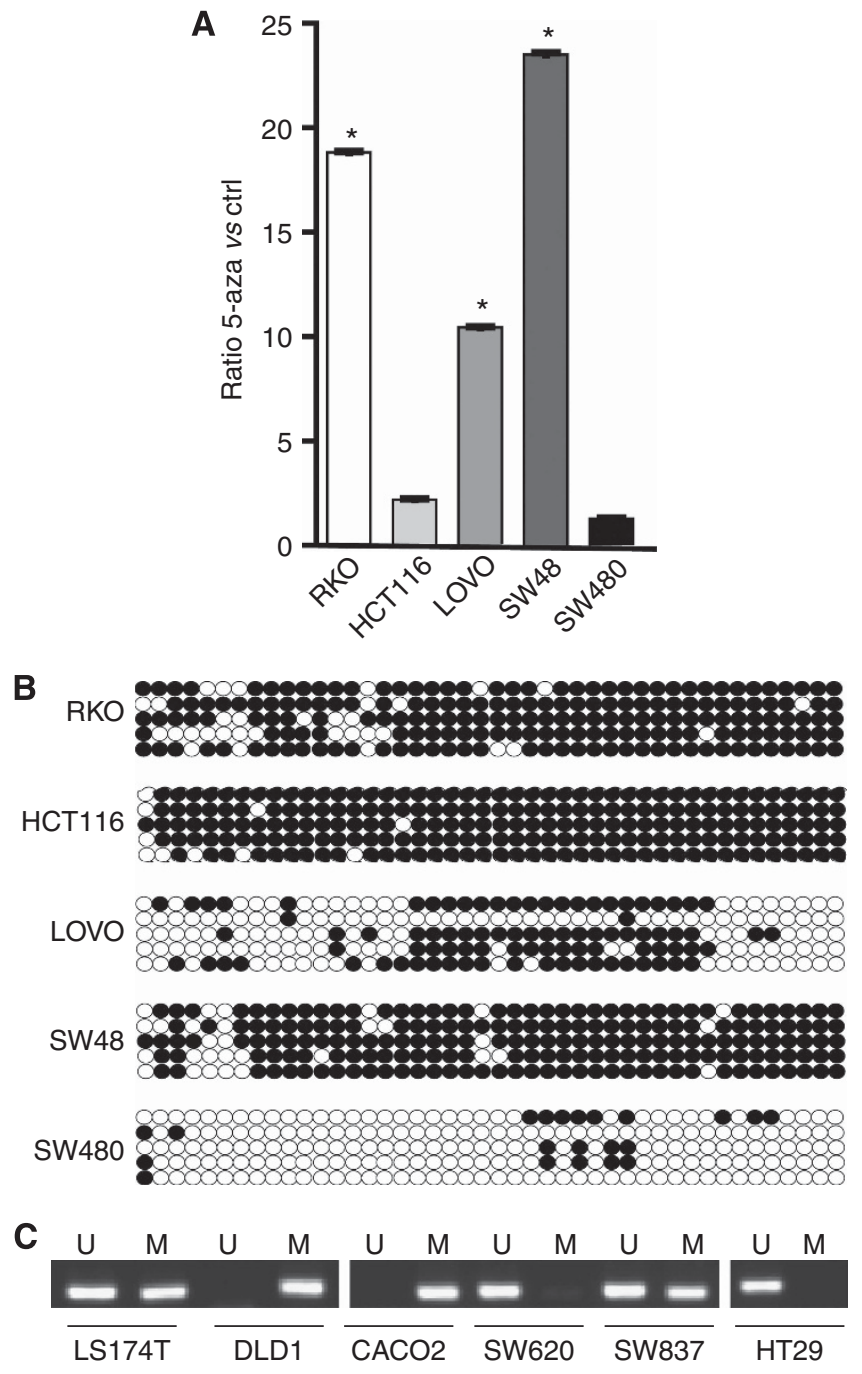

Figure 1. Epigenetic regulation of VANGL2 in a panel of CRC cell lines with different MSI status. (A) Ratio between VANGL2 mRNA expression in each cell line after and before 5-aza treatment (ratio 5-aza vs ctrl; (B) Representative bisulphite sequencing on five different clones. Methylation status of each individual promoter is shown as a row of $\mathrm{CpG}$ sites (empty dot $=\mathrm{CpG}$ unmethylated; solid dot $=\mathrm{CpG}$ methylated); (C) Methylation-specific PCR (MSP: U = unmethylated; $\mathrm{M}=$ methylated). ${ }^{*} \mathrm{P}<0.05$ (unpaired $\mathrm{t}$-test). 

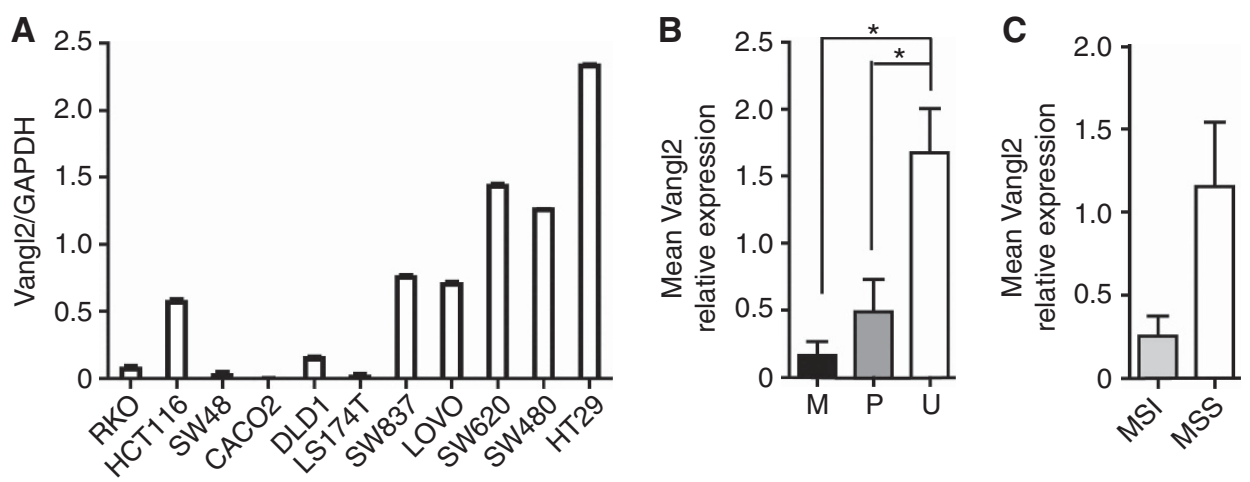

Figure 2. VANGL2 mRNA expression in CRC cell lines. (A) Quantitative RT-PCR of VANGL2 mRNA; GAPDH was used as normaliser; (B) mean VANGL2 mRNA expression by methylation status ( $\mathrm{M}=$ methylated; $\mathrm{P}=$ partially methylated; $\mathrm{U}=$ unmethylated); (C) mean VANGL2 mRNA expression by MSI status. ${ }^{\star} P<0.05$.

\begin{tabular}{|c|c|}
\hline Characteristic & Patients, $\boldsymbol{n}(\%)$ \\
\hline Age (years \pm s.d.) & $67.1 \pm 11.1$ \\
\hline $\operatorname{Sex}(M, F)$ & M 224 (53.6\%); F 194 (46.4\%) \\
\hline Site $(R C, L C, R)$ & RC 159 (38.1\%); LC 154 (36.8\%); R 105 (25.1\%) \\
\hline Grade (G1, G2, G3) & G1 34 (8.4\%); G2 297 (73.2\%); G3 75 (18.5\%) \\
\hline Stage (II, III, IV) & II 190 (45.5\%); III 138 (33\%); IV 90 (21.5\%) \\
\hline MSI status (MSI, MSS) & MSI 35 (8.93\%); MSS 357 (91.07\%) \\
\hline
\end{tabular}

To explore the potential role of methylation in the regulation of VANGL2 mRNA expression, we analysed the VANGL2 promoter and $5^{\prime} \mathrm{UTR}$ looking for $\mathrm{CpG}$ islands. Bisulphite sequencing of multiple clones of RKO, SW48, HCT116, LOVO and SW480 was performed to determine the methylation status of the VANGL2 promoter and $5^{\prime} \mathrm{UTR}$ in these cell lines (Figure 1B). Moreover, MSP was done on six additional CRC cell lines with different MSI status (MSI: LS174T and DLD1; MSS: Caco2, SW620, SW837 and HT29; Figure 1C). We found that the VANGL2 promoter was fully methylated in RKO, SW48, HCT116 and DLD1; partially methylated in LOVO, LS174T and SW837; and unmethylated in SW480, SW620 and HT29. Then, Q-RT-PCR was performed to measure VANGL2 mRNA level in the full panel of CRC cell lines (Figure 2A). In accordance with VANGL2 promoter methylation status, we found higher expression of VANGL2 mRNA in the unmethylated cell lines compared with methylated and partially methylated cell lines (Figure 2B). Interestingly, we found higher expression of VANGL2 in MSS cell lines compared with MSI cells lines, although it did not reach statistical significance (Figure 2C). Our data indicate that VANGL2 promoter hypermethylation is associated with VANGL2 silencing in CRC cell lines, and is frequent in MSI cell lines.

VANGL2 is methylated in CRC tissues. To determine whether VANGL2 is methylated in clinical specimens, we analysed VANGL2 promoter by MSP in 17 normal colon and 418 primary CRC tissues. Clinico-pathological features of CRC patients are reported in Table 1; MSI in 'Bologna samples' was 13.6\% (16 MSI; 102 MSS); MSI 'Milan samples' was 6.93\% (19 MSI; 255 MSS). A representative image of MSP analysis on patient samples is reported in Supplementary Figure 2; methylation was defined as the presence of a solid methylation-specific fragment in MSP gels.

\begin{tabular}{|c|c|c|c|}
\hline & Vangl2 M & Vangl2 U & $P$ \\
\hline MSI status & $\begin{array}{l}20.4 \% \text { MSI }(21 / 103) \\
79.6 \% \text { MSS (82/103) }\end{array}$ & $\begin{array}{c}\text { 4.5\% MSI (13/286) } \\
95.5 \% \text { MSS (273/286) }\end{array}$ & $<0.0001$ \\
\hline Grade & $\begin{array}{l}7.5 \% \text { G1 }(8 / 106) \\
60.4 \% \text { G2 }(64 / 106) \\
32.1 \% \text { G3 }(34 / 106)\end{array}$ & $\begin{array}{c}8.8 \% \text { G1 }(26 / 297) \\
77.4 \% \text { G2 (230/297) } \\
13.8 \% \text { G3 (41/297) }\end{array}$ & 0.0002 \\
\hline Site & $\begin{array}{c}64.8 \% \text { RC (68/105) } \\
19 \% \text { LC (20/105) } \\
16.2 \% \text { R (17/105) }\end{array}$ & $\begin{array}{c}28.8 \% \text { RC (89/309) } \\
42.7 \% \text { LC (132/309) } \\
28.5 \% \text { R (88/309) }\end{array}$ & $<0.0001$ \\
\hline BRAF V600E & $\begin{array}{l}22.9 \% \text { mut }(11 / 48) \\
77.1 \% \text { wt }(37 / 48)\end{array}$ & $\begin{array}{c}6.5 \% \text { mut }(8 / 124) \\
93.5 \% \text { wt }(116 / 124)\end{array}$ & 0.002 \\
\hline \multicolumn{4}{|c|}{$\begin{array}{l}\text { Abbreviations: Grade } G 1, G 2, G 3=\text { grade low, intermediate, high, respectively; } \\
\text { LC=left colon; } M=\text { =methylated; } M S I=\text { microsatellite unstable, } M S S=\text { microsatellite stable; } \\
\text { mut = mutated; } R=\text { rectum; } R C=\text { right colon; } U=\text { unmethylated; } w t=\text { wild type. }\end{array}$} \\
\hline
\end{tabular}

We found that VANGL2 promoter was methylated in 106 out of 418 CRC patients (25.3\%), but in none of the normal colon tissues. We examined associations between VANGL2 methylation and clinico-pathological features $\left(\chi^{2}\right.$ and Fisher's exact test were applied). Interestingly, VANGL2 methylation was significantly more common in MSI tumours than in MSS tumours $(P<0.0001$, Table 2). This relationship was reflected in associations between VANGL2 methylation and MSI-associated tumour features, including higher grade $(P=0.0002)$, proximal colon location $(P<0.0001)$ and BRAF V600E mutation $(P=0.002$; Table 2$)$. Furthermore, a multi-way correspondence analysis confirmed a strong clustering among VANGL2 methylation, MSI, BRAF V600E mutation, higher grade and proximal colon location, whereas a weaker association was found among Vangl2 unmethylated, MSS, BRAF wild type, left colon and lower-intermediate grade (Supplementary Figure 3). In addition, a regression analysis was performed to confirm that Vangl2 methylation is independently associated with higher grade, proximal colon location and BRAF mutation (Supplementary Table 2). This data suggest that VANGL2 promoter hypermethylation is associated with MSI and CIMP CRC in vivo, confirming our findings in vitro.

Van-Gogh-like 2 expression in CRC cells inhibits cell growth and clonogenicity. To evaluate the functional role of VANGL2 in CRC cell lines, we transfected a VANGL2-expressing vector and its control vector into SW480 cells. After G418 selection, we compared proliferation and colony-forming abilities in SW480- 
CTRL and SW480-VANGL2. MTT assay showed that ectopic expression of VANGL2 induced a significant reduction in SW480 cell proliferation $(P=0.0019$; Figure $3 \mathrm{~A})$. Moreover, VANGL2
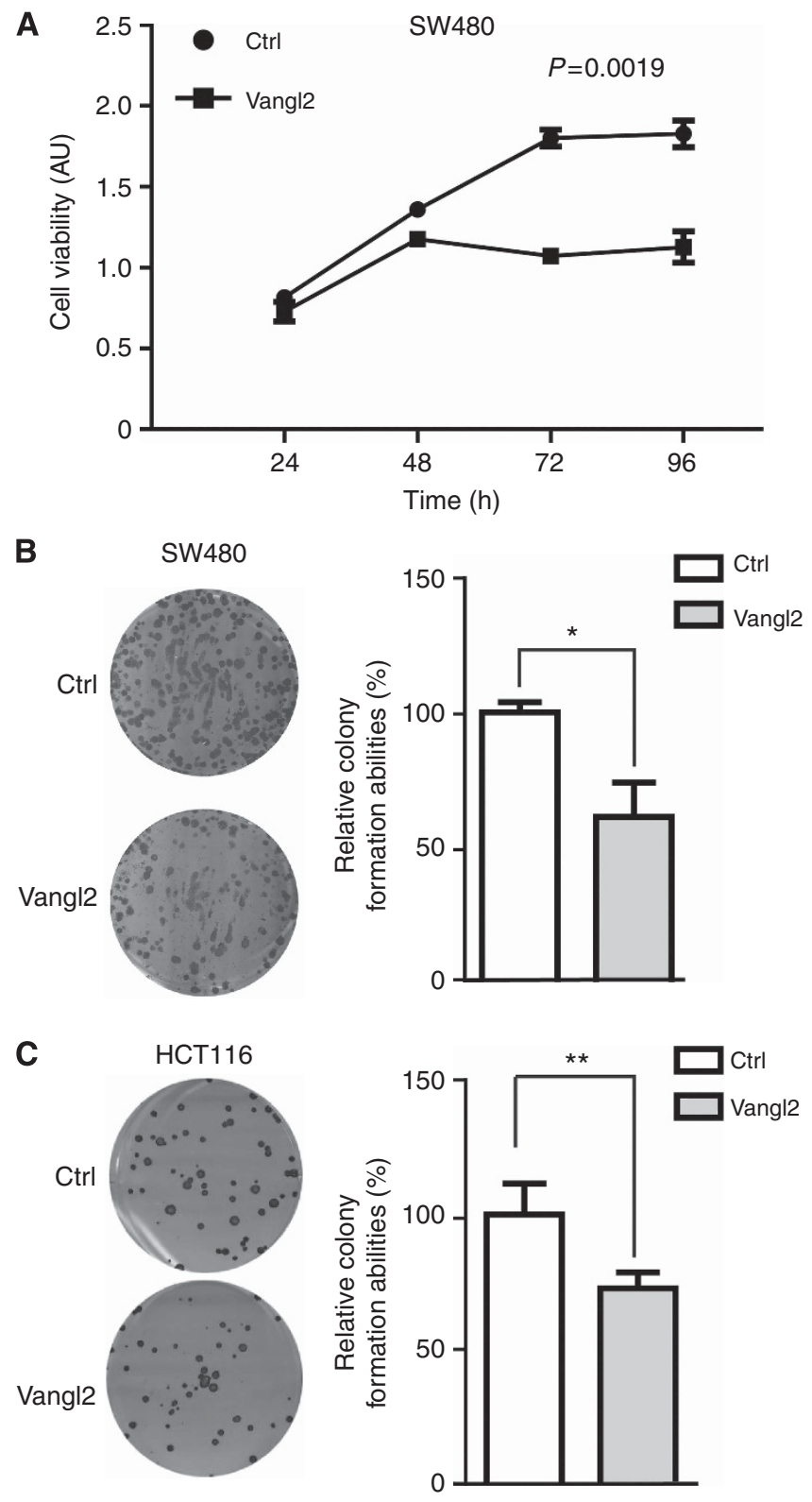

Figure 3. VANGL2 suppresses cell growth and clonogenicity by canonical WNT modulation. (A) Van-Gogh-like 2 inhibits cell growth in SW480-VANGL2 cells, and (B) colony formation in SW480-VANGL2 cells; (C) VANGL2 inhibits cell colony formation in HCT116-VANGL2. ${ }^{\star} P=0.0004 ;{ }^{*} P=0.0121$. $\mathrm{AU}=$ arbitrary units. overexpression significantly inhibited colony formation $(P=0.0004$; Figure $3 \mathrm{~B})$. This latter result was confirmed after the stable overexpression of VANGL2 in HCT116, a cell line that shows VANGL2 promoter methylation $(P=0.0121$, Figure $3 \mathrm{C})$.

Van-Gogh-like 2 expression in CRC cells inhibits WNT/ $\beta$ catenin signaling. To study the effect of VANGL2 modulation on canonical $\mathrm{WNT} / \beta$-catenin signaling, we determined $\beta$-catenin levels by immunofluorescence microscopy (Figure 4A) and analysed $\beta$-catenin/TCF-dependent transcription in luciferase reporter assays (Figure 4B, left) before and after VANGL2 overexpression in SW480. In VANGL2-transfected SW480 cells, $\beta$-catenin levels were decreased compared with SW480-CTRL (Figure 4A). These results suggest that VANGL2 negatively regulates intracellular levels of $\beta$-catenin. In accordance with downregulation, the luciferase activity of the TCF luciferase reporter TOPflash was significantly decreased (about 47\%) in SW480-VANGL2 cells $(P=0.0002$; Figure $4 \mathrm{~B}$, left). This result further confirmed that VANGL2 counteracts canonical WNT signaling in CRC cells. We also studied the effect of VANGL2 on the expression of two $\beta$-catenin target genes, Cyclin D1 and c-Myc (Figure 4B, right). Our results show a downregulation of Cyclin D1 and c-Myc in SW480-VANGL2, in accordance with the decrease of $\beta$-catenin intracellular levels and activity.

\section{DISCUSSION}

In this study, we found that the expression of VANGL2, a transmembrane protein that participates in non-canonical WNT signaling, is regulated by promoter hypermethylation in CRC cell lines. In addition, the VANGL2 promoter is frequently aberrantly methylated in CRC tissues displaying MSI. Importantly, we demonstrate that forced overexpression of VANGL2 inhibits proliferation and colony-forming ability in CRC cell lines, and this effect can be mediated by inhibition of canonical WNT signaling. Our results support the concept that loss of VANGL2 activates canonical WNT signaling, with a potential pro-tumourigenic effect in CRC.

CRC is the third leading cause of cancer deaths in the United States (Siegel et al, 2012). Colorectal cancer develops as a consequence of genetic and epigenetic alterations in TSGs and oncogenes that lead to genomic instability, a feature that affects all pathways involved in CRC pathogenesis (Grady and Carethers, 2008). Most CRCs arise through the CIN pathway and are characterised by aneuploidy, loss of heterozygosity and are MSS (Pino and Chung, 2010). Approximately 15\% of CRCs arise through the MSI pathway, which is a hallmark of DNA-mismatch repair-deficient CRCs. Sporadic MSI CRCs exhibit unique clinicopathologic features such as diploidy, poor differentiation, mucinous histology, lymphocytic infiltrates, older age, proximal colon location, BRAF V600E mutation, a better prognosis and resistance to 5-fluorouracil-based chemotherapy, which distinguishes them from CIN tumours. BRAF V600E mutation is strongly associated
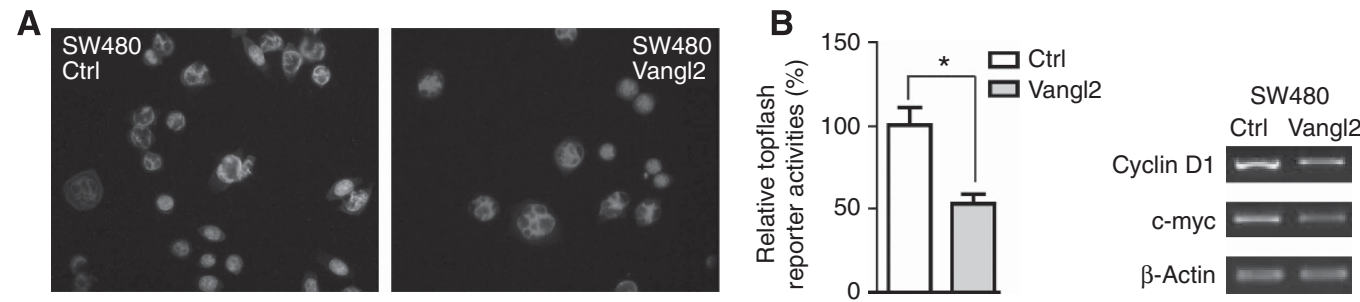

Figure 4. VANGL2 represses canonical WNT signaling. (A) Immunofluorescence microscopy for $\beta$-catenin in SW480. (B) VANGL2 decreases $\beta$-catenin/TCF luciferase reporter activity (left) and transcription of $\beta$-catenin target genes cyclin-D1 and C-Myc (right) in SW480-VANGL2; ${ }^{\star} P=0.0002$. 
with CIMP (Weisenberger et al, 2006). In this study, we found that VANGL2 gene expression is controlled by promoter hypermethylation. Indeed, pharmacological treatment with the demethylating agent 5-aza-2'-deoxycytidine strongly upregulated the expression of VANGL2 in the fully methylated cell lines RKO and SW48 (models of MSI-CIMP; both hypermethylated at hMLH1) and in the hemimethylated cell line LOVO (a model of Lynch syndrome, mutated at hMSH2). A smaller increase in VANGL2 re-expression was found in HCT116 (a model of Lynch syndrome, mutated at hMLH1) that has a VANGL2 promoter more heavily methylated compared with other cell lines. As expected, no differences in the expression of VANGL2 after 5-aza treatment were found in SW480, a model of MSS CRC with a low rate of methylation at CpGs islands. Additional confirmation that promoter methylation represses VANGL2 expression was found in the analysis of a panel of 11 CRC cell lines. Increased mean VANGL2 levels were associated with unmethylated and partially methylated (or hemimethylated) cell lines compared with fully methylated ones. Although there is an overall correlation between Vangl2 promoter methylation and lack of expression, there are some exceptions to this. For instance, HCT116 cells have a highly methylated promoter but express VANGL2 at a level comparable to LOVO and SW837 (hemimethylated cell lines). With respect to the VANGL2 promoter region investigated in this study, we cannot exclude that a wider promoter portion could account for its expression, thus also possibly explaining for VANGL2 pattern in HCT116 cells. Interestingly, VANGL2 levels were lower in MSI CRC cell lines, suggesting that VANGL2 methylation is predominant in this subtype, even if the sample size was too limited for statistical analyses. In accordance with this observation, we found that VANGL2 promoter methylation is a feature of MSI CRCs. Importantly, VANGL2 methylation was associated with clinicopathologic features of this subtype (i.e., higher grade, proximal colon location, BRAF V600E mutation), also independently from MSI. The association of Vangl2 methylation with BRAF V600E mutation suggests an association with CIMP that is tightly connected with sporadic MSI, though we did not analyse CIMP markers. Constitutive activation of the WNT/ $\beta$-catenin signaling pathway occurs in nearly all CRCs due to both genetic and epigenetic mechanisms. Most CRCs harbour somatic mutations in APC or, less frequently, in $\beta$-catenin or AXIN2 (Segditsas and Tomlinson, 2006), whereas epigenetic silencing has been reported for APC and for the WNT antagonists SFRP, DKK-1 and WIF1 (Hiltunen et al, 1997; Suzuki et al, 2004; Taniguchi et al, 2005; Aguilera et al, 2006). Epigenetic changes have been reported in noncanonical WNT proteins such as WNT5a (Ying et al, 2008) and Ror2 (Lara et al, 2010). It is known that WNT5a signals through Ror 2 to inhibit $\beta$-catenin signaling (Oishi et al, 2003), and recently, it has been shown that VANGL2 forms a WNT5a-induced receptor complex with Ror2 to transduce its signal (Gao et al, 2011). Consistent with these findings, we found that the forced overexpression of VANGL2 in SW480, a cell line that expresses both WNT-5a and Ror-2 proteins (Ying et al, 2008; Lara et al, 2010), results in strong inhibition of WNT/ $\beta$-catenin signaling and the target genes Cyclin D1 and $\mathrm{c}-\mathrm{Myc}$ by reducing intracellular $\beta$ catenin protein expression. In addition, our finding that VANGL2 inhibits colony-forming ability and growth of CRC cells is consistent with the effect of WNT5a and Ror2 overexpression in CRC cell lines (Ying et al, 2008; Lara et al, 2010). These lines of evidence suggest that VANGL2 might act as a tumour suppressor in $\mathrm{CRC}$, and are in agreement with its role as invasion suppressor in fibrosarcoma cells (Cantrell and Jessen, 2010). We speculate that the epigenetic inactivation of VANGL2 in MSI CRCs could be advantageous in this subtype of cancers that might benefit from an increase in $\beta$-catenin activity and WNT signaling.

In conclusion, the data reported here add important new insights into the precise methylation events that contribute to MSI
CRCs biology and might be useful to better understand the behaviour of this distinct class of tumours.

\section{ACKNOWLEDGEMENTS}

This study was supported by the Italian Association for Cancer Research (AIRC), investigator grant 10216 (to LR). We thank Dr Filomena d'Orio for technical support.

\section{REFERENCES}

Aguilera O, Fraga MF, Ballestar E, Paz MF, Herranz M, Espada J, Garcia JM, Munoz A, Esteller M, Gonzalez-Sancho JM (2006) Epigenetic inactivation of the Wnt antagonist DICKKOPF-1 (DKK-1) gene in human colorectal cancer. Oncogene 25(29): 4116-4121.

Barrow JR (2006) Wnt/PCP signaling: a veritable polar star in establishing patterns of polarity in embryonic tissues. Semin Cell Dev Biol 17(2): 185-193.

Baylin SB, Ohm JE (2006) Epigenetic gene silencing in cancer - a mechanism for early oncogenic pathway addiction? Nat Rev Cancer 6(2): 107-116.

Boland CR, Goel A (2010) Microsatellite instability in colorectal cancer. Gastroenterology 138(6): 2073-2087 e3.

Boland CR, Thibodeau SN, Hamilton SR, Sidransky D, Eshleman JR, Burt RW, Meltzer SJ, Rodriguez-Bigas MA, Fodde R, Ranzani GN, Srivastava S (1998) A National cancer institute workshop on microsatellite instability for cancer detection and familial predisposition: development of international criteria for the determination of microsatellite instability in colorectal cancer. Cancer Res 58(22): 5248-5257.

Cantrell VA, Jessen JR (2010) The planar cell polarity protein Van Gogh-Like 2 regulates tumor cell migration and matrix metalloproteinase-dependent invasion. Cancer Lett 287(1): 54-61.

Gao B, Song H, Bishop K, Elliot G, Garrett L, English MA, Andre P, Robinson J, Sood R, Minami Y, Economides AN, Yang Y (2011) Wnt signaling gradients establish planar cell polarity by inducing Vangl2 phosphorylation through Ror2. Dev Cell 20(2): 163-176.

Grady WM, Carethers JM (2008) Genomic and epigenetic instability in colorectal cancer pathogenesis. Gastroenterology 135(4): 1079-1099.

Greenacre M (1984) Theory and Applications of Correspondence Analysis. London: Academic Press.

Hiltunen MO, Alhonen L, Koistinaho J, Myohanen S, Paakkonen M, Marin S, Kosma VM, Janne J (1997) Hypermethylation of the APC (adenomatous polyposis coli) gene promoter region in human colorectal carcinoma. Int J Cancer 70(6): 644-648.

Iliescu A, Gravel M, Horth C, Apuzzo S, Gros P (2011) Transmembrane topology of mammalian planar cell polarity protein Vangl1. Biochemistry 50(12): 2274-2282.

Kane MF, Loda M, Gaida GM, Lipman J, Mishra R, Goldman H, Jessup JM, Kolodner R (1997) Methylation of the hMLH1 promoter correlates with lack of expression of hMLH1 in sporadic colon tumors and mismatch repair-defective human tumor cell lines. Cancer Res 57(5): 808-811.

Kibar Z, Salem S, Bosoi CM, Pauwels E, De Marco P, Merello E, Bassuk AG, Capra V, Gros P (2011) Contribution of VANGL2 mutations to isolated neural tube defects. Clin Genet 80(1): 76-82.

Kibar Z, Vogan KJ, Groulx N, Justice MJ, Underhill DA, Gros P (2001) Ltap, a mammalian homolog of Drosophila Strabismus/Van Gogh, is altered in the mouse neural tube mutant Loop-tail. Nat Genet 28(3): 251-255.

Laghi L, Bianchi P, Malesci A (2008) Differences and evolution of the methods for the assessment of microsatellite instability. Oncogene 27(49): 6313-6321.

Lara E, Calvanese V, Huidobro C, Fernandez AF, Moncada-Pazos A, Obaya AJ, Aguilera O, Gonzalez-Sancho JM, Sanchez L, Astudillo A, Munoz A, Lopez-Otin C, Esteller M, Fraga MF (2010) Epigenetic repression of ROR2 has a Wnt-mediated, pro-tumourigenic role in colon cancer. Mol Cancer 9: 170 .

Lei YP, Zhang T, Li H, Wu BL, Jin L, Wang HY (2010) VANGL2 mutations in human cranial neural-tube defects. N Engl J Med 362(23): 2232-2235.

Li S, Esterberg R, Lachance V, Ren D, Radde-Gallwitz K, Chi F, Parent JL, Fritz A, Chen P (2011) Rack1 is required for Vangl2 membrane localization and planar cell polarity signaling while attenuating canonical Wnt activity. Proc Natl Acad Sci USA 108(6): 2264-2269. 
Lindqvist M, Horn Z, Bryja V, Schulte G, Papachristou P, Ajima R, Dyberg C, Arenas E, Yamaguchi TP, Lagercrantz H, Ringstedt T (2010) Vang-like protein 2 and Racl interact to regulate adherens junctions. J Cell Sci 123(Pt 3): 472-483.

Logan CY, Nusse R (2004) The Wnt signaling pathway in development and disease. Annu Rev Cell Dev Biol 20: 781-810.

Oishi I, Suzuki H, Onishi N, Takada R, Kani S, Ohkawara B, Koshida I, Suzuki K, Yamada G, Schwabe GC, Mundlos S, Shibuya H, Takada S, Minami Y (2003) The receptor tyrosine kinase Ror2 is involved in non-canonical Wnt5a/JNK signalling pathway. Genes Cells 8(7): 645-654.

Pino MS, Chung DC (2010) The chromosomal instability pathway in colon cancer. Gastroenterology 138(6): 2059-2072.

Rawson JB, Mrkonjic M, Daftary D, Dicks E, Buchanan DD, Younghusband HB, Parfrey PS, Young JP, Pollett A, Green RC, Gallinger S, McLaughlin JR, Knight JA, Bapat B (2011) Promoter methylation of Wnt5a is associated with microsatellite instability and BRAF V600E mutation in two large populations of colorectal cancer patients. Br J Cancer 104(12): 1906-1912.

Reya T, Clevers H (2005) Wnt signalling in stem cells and cancer. Nature 434(7035): 843-850.

Ricciardiello L, Ceccarelli C, Angiolini G, Pariali M, Chieco P, Paterini P, Biasco G, Martinelli GN, Roda E, Bazzoli F (2005) High thymidylate synthase expression in colorectal cancer with microsatellite instability: implications for chemotherapeutic strategies. Clin Cancer Res 11(11): 4234-4240.

Segditsas S, Tomlinson I (2006) Colorectal cancer and genetic alterations in the Wnt pathway. Oncogene 25(57): 7531-7537.

Siegel R, Naishadham D, Jemal A (2012) Cancer statistics, 2012. CA Cancer J Clin 62(1): 10-29.

Sinicrope FA, Sargent DJ (2012) Molecular pathways: microsatellite instability in colorectal cancer: prognostic, predictive, and therapeutic implications. Clin Cancer Res 18(6): 1506-1512.

Suzuki H, Watkins DN, Jair KW, Schuebel KE, Markowitz SD, Chen WD, Pretlow TP, Yang B, Akiyama Y, Van Engeland M, Toyota M, Tokino T, Hinoda Y, Imai K, Herman JG, Baylin SB (2004) Epigenetic inactivation of SFRP genes allows constitutive WNT signaling in colorectal cancer. Nat Genet 36(4): 417-422.

Taniguchi H, Yamamoto H, Hirata T, Miyamoto N, Oki M, Nosho K, Adachi Y, Endo T, Imai K, Shinomura Y (2005) Frequent epigenetic inactivation of Wnt inhibitory factor-1 in human gastrointestinal cancers. Oncogene 24(53): 7946-7952.

Taylor J, Abramova N, Charlton J, Adler PN (1998) Van Gogh: a new Drosophila tissue polarity gene. Genetics 150(1): 199-210.

Torban E, Wang HJ, Groulx N, Gros P (2004) Independent mutations in mouse Vangl2 that cause neural tube defects in looptail mice impair interaction with members of the Dishevelled family. J Biol Chem 279(50): 52703-52713.

Toyota M, Ahuja N, Ohe-Toyota M, Herman JG, Baylin SB, Issa JP (1999) CpG island methylator phenotype in colorectal cancer. Proc Natl Acad Sci USA 96(15): 8681-8686.

Veeman MT, Axelrod JD, Moon RT (2003) A second canon. Functions and mechanisms of beta-catenin-independent Wnt signaling. Dev Cell 5(3): 367-377.

Weisenberger DJ, Siegmund KD, Campan M, Young J, Long TI, Faasse MA, Kang GH, Widschwendter M, Weener D, Buchanan D, Koh H, Simms L, Barker M, Leggett B, Levine J, Kim M, French AJ, Thibodeau SN, Jass J, Haile R, Laird PW (2006) CpG island methylator phenotype underlies sporadic microsatellite instability and is tightly associated with BRAF mutation in colorectal cancer. Nat Genet 38(7): 787-793.

Williams BB, Cantrell VA, Mundell NA, Bennett AC, Quick RE, Jessen JR (2012) VANGL2 regulates membrane trafficking of MMP14 to control cell polarity and migration. J Cell Sci 125(Pt 9): 2141-2147.

Wolff T, Rubin GM (1998) Strabismus, a novel gene that regulates tissue polarity and cell fate decisions in Drosophila. Development 125(6): 1149-1159.

Ying J, Li H, Yu J, Ng KM, Poon FF, Wong SC, Chan AT, Sung JJ, Tao Q (2008) WNT5A exhibits tumor-suppressive activity through antagonizing the Wnt/beta-catenin signaling, and is frequently methylated in colorectal cancer. Clin Cancer Res 14(1): 55-61.

This work is published under the standard license to publish agreement. After 12 months the work will become freely available and the license terms will switch to a Creative Commons AttributionNonCommercial-Share Alike 3.0 Unported License.

Supplementary Information accompanies this paper on British Journal of Cancer website (http://www.nature.com/bjc) 